\title{
SIMPLICIDADE VOLUNTÁRIA: ESCOLHENDO UMA NOVA FORMA DE VIVER
}

\section{VOLUNTARY SIMPLICITY: CHOOSING A NEW WAY TO LIVE}

\author{
Renata Céli Moreira da Silva \\ Doutora em Administração \\ Pontifícia Universidade Católica do Rio de Janeiro - IAG - Pontifícia Universidade Católica do Rio de Janeiro. \\ Rio de Janeiro, RJ, Brasil \\ E-mail: renata.celi@gmail.com \\ Luis Fernando Hor-Meyll \\ Doutorado em Administração pela Universidade Federal do Rio de Janeiro / COPPEAD (2004). Professor do \\ quadro principal do IAG - Pontifícia Universidade Católica do Rio de Janeiro. \\ Rio de Janeiro, RJ, Brasil \\ E-mail: hormeyll@iag.puc-rio.br
}

\section{RESUMO}

O estudo investigou motivações de consumidores para adotar a simplicidade voluntária e os impactos causados em suas vidas. Durante dez meses, foram acompanhados os debates de um grupo sobre o tema no Facebook e conduzidas treze entrevistas em profundidade com participantes do grupo. Através de análise de conteúdo, surgiram evidências de que as principais motivações para a adoção da simplicidade voluntária são de natureza pessoal, levando a mudanças que afetam ocupação profissional, moradia, transporte, alimentação, consumo e descarte de bens, organização pessoal e consciências ecológica e social. Diversos benefícios da adoção da vida simples foram apontados, além de algumas consequências negativas para a vida dos adotantes. São oferecidas proposições decorrentes do estudo para orientar pesquisas futuras.

Palavras-chave: Comportamento do Consumidor. Simplicidade Voluntária. Anticonsumo no Brasil.

Data de submissão: 25 de abril de 2016.

\section{ABSTRACT}

The study investigated consumers' motivations for adopting voluntary simplicity and the impacts it caused on their lives. For ten months, discussions on a Facebook group on the theme were monitored. Thirteen in-depth interviews with group participants were also conducted. Through content analysis, evidence emerged that the main motivations for adopting voluntary simplicity are of personal nature, leading to changes that affect work, housing, transportation, nutrition, consumption and disposal of goods, personal organization, and ecological and social consciousness. Several benefits of adopting a simpler life were pointed out, besides some negative consequences for the lives of the adopters. Propositions arising from the study are offered to orient future research.

Keywords: Marketing. Consumer Behavior. Voluntary Simplicity. Anti consumption in Brazil.

Data de aprovação: 22 de julho de 2016.




\section{INTRODUÇÃO}

A Revolução Industrial levou a sociedade a ser cada vez mais dependente da posse de bens e de práticas de consumo (MCCRACKEN, 2003) - surgiu a "sociedade de consumo" (BAUDRILLARD, 2008), caracterizada fundamentalmente pelo materialismo (CLEVELAND; CHANG, 2009), voltada para a aquisição, posse e consumo de bens (SHAW; NEWHOLM, 2002).

Murphy (2000) observou que os indivíduos passaram a acreditar que seus problemas seriam resolvidos com o consumo, que se tornara um meio para obter status no grupo social e, também, de autovalorização (GREGG, 1977; KIRON, 1997). O consumo passou a ter significados simbólicos (LEVY, 1959; BAUDRILLARD, 2000), assumindo papel importante para expressão individual e em relações sociais (GOODWIN, 1997).

A sofisticação dos meios de produção provocou aceleração da produção e acirramento da competição, contribuindo para a aceleração na dinâmica do consumo. Além disso, surgiram produtos descartáveis, que acentuaram a dinâmica, pois o descarte passou a ocorrer em intervalos de tempo cada vez menores, dando lugar a novos produtos (CHAUVEL; SUAREZ, 2009).

A partir das discussões sobre a sociedade de consumo, surgiram questionamentos sobre impactos ambientais e sociais decorrentes (CSIKSZENTMIHALYI, 1999), despertando reflexões sobre as razões que levavam os indivíduos a consumir (ETZIONI, 1998; SHAW; NEWHOLM, 2002). Estudos sobre a relação entre felicidade, riqueza e consumo (CSIKSZENTMIHALYI, 1999; HSEE, YANG, LI et al., 2009) sugerem que elevado consumo não leva necessariamente à felicidade do indivíduo (CSIKSZENTMIHALYI, 1999; AHUVIA, 2008) nem à melhora da qualidade de vida (CSIKSZENTMIHALYI, 2000; KARABATI; CEMALCILAR, 2010). O excesso na posse de bens materiais poderia até indicar um indivíduo insatisfeito com a vida (CSIKSZENTMIHALYI, 2000), embora Lee, Sirgy, Larsen et al. (2002) considerem que a satisfação com o consumo poderia ser um fator que traga satisfação com a vida.

Como reação de indivíduos a impactos identificados do consumismo, surgiram diversos comportamentos anticonsumo (AHUVIA, 2008). Alguns anticonsumidores criticam os altos níveis de consumo da sociedade, apontando consequências negativas para as pessoas e para o meio ambiente (AHUVIA, 2008). Uma das tendências surgidas é um estilo de vida alternativo - a busca por uma vida mais simples (SHAW; NEWHOLM, 2002; ASSADOURIAN, 2010), a simplicidade voluntária.

O estudo sobre a simplicidade voluntária ainda é incipiente na literatura de Marketing (CRAIG-LEES; HILL, 2002), principalmente no Brasil, onde grande parte da população somente recentemente começou a ter acesso a níveis mais elevados de consumo, além da subsistência (ROCHA; SILVA, 2008). É curioso notar que, enquanto existem consumidores ávidos por adquirir produtos e serviços que antes lhes eram inacessíveis, há um grupo pequeno de indivíduos que têm optado, de forma voluntária, por reduzir seu consumo.

O objetivo deste trabalho foi investigar os motivos que levam indivíduos a adotarem a simplicidade voluntária e como essa mudança de comportamento impacta suas vidas. É relevante estudar a simplicidade voluntária no Brasil, já que o fenômeno pode causar mudanças em comportamentos de compra e no uso de produtos e serviços (JOHNSTON; BURTON, 2003), com implicações para empresas e para a sociedade (ELGIN; MITCHELL, 1977a). 


\section{O QUE É SIMPLICIDADE VOLUNTÁRIA}

O termo teve origem no trabalho de Richard Gregg (1936) (ELGIN; MITCHELL, 1977a; LEONARDBURTON, 1981), que o definiu como um estilo de vida ligado à dimensão espiritual do homem, quando o indivíduo abre mão de vida materialista (LEONARD-BURTON, 1981) e evita o acúmulo de posses desnecessárias (BALLANTINE; CREERY, 2010).

Um estudo teórico pioneiro foi conduzido por Elgin e Mitchell (1977b) e, apesar de ter sido publicado em revista sem caráter científico, é hoje considerado seminal sobre simplicidade voluntária. A principal razão da sua adoção seria o desejo do indivíduo de encontrar equilíbrio ao viver de forma "aparentemente simples e interiormente rica", representando verdadeira mudança de valores (ELGIN; MITCHELL, 1977b, p. 2). A revista enviada para os leitores incluiu um questionário em que deveriam indicar hábitos para uma vida simples.

Posteriormente, Elgin publicou o livro "Simplicidade Voluntária", apresentado nas livrarias na categoria de autoajuda. O livro foi baseado nas respostas colhidas nos questionários distribuídos com a revista de 1977. Recentemente, nova edição foi publicada, relacionando a simplicidade voluntária a um estilo de vida responsável por diminuir impactos globais e ajudar a resolver problemas ambientais (ELGIN, 2012).

Outros autores estudaram a simplicidade voluntária. Gregg (1977) destacou que a simplicidade pode variar de acordo com o clima, com a cultura e com características pessoais do indivíduo, não apresentando um padrão único - o que é simplicidade para um pode ser diferente para outro, principalmente se a comparação for entre diferentes culturas.

Etzioni (1998) definiu simplicidade voluntária como a escolha por reduzir gastos com consumo, valorizando a satisfação não material, uma escolha voluntária que não seria motivada por coerção ou por condições financeiras desfavoráveis. Posteriormente, Elgin (2000) sublinhou que a simplicidade não teria relação com pobreza, que é uma condição involuntária que leva à redução do consumo.

\section{MOTIVAÇÕES PARA ADOTAR A SIMPLICIDADE VOLUNTÁRIA}

Elgin e Mitchell (1977b) propuseram que os valores fundamentais da simplicidade voluntária seriam:

- Simplicidade material - Ter vida não consumista, já que o importante é ser e não ter. Consumir em menor quantidade. Preferir bens duráveis e eficientes, com menos impactos ambientais e sociais. Comprar o necessário e reduzir excessos.

- Escala humana - Reduzir a complexidade da vida, valorizando produtos manufaturados, ao invés de industrializados.

- Autodeterminação -Maior controle pessoal e autossuficiência.

- Consciência ambiental - Conservação dos recursos do planeta.

- Crescimento pessoal - Autorrealização, crescimento espiritual e psicológico, aspectos ligados à 'vida interior'. 
Com base em motivações, Leonard-Barton (1981) classificou os praticantes da simplicidade voluntária em três grupos: os conservers (conservadores), que nasceram em famílias severas em relação a desperdício. Geralmente, alguém da família foi pobre na infância ou morou em um país em desenvolvimento. Os crusaders, que vieram de famílias com valores éticos voltados para a conservação e para a responsabilidade social. Os conformists que adotam a simplicidade voluntária por razões menos claras: alguns por culpa, por serem ricos, outros porque foram influenciados por outros.

As motivações que hoje levam à adesão da simplicidade voluntária são novas e diferentes. Oates, McDonald, Alevizou et al. (2008) observaram que alguns autores consideram a simplicidade voluntária como proveniente de motivação pessoal, como a redução do estresse, enquanto que outros apontam motivações sociais, ambientais e ética.

Elgin e Mitchell (1977b) acreditam que as motivações estão relacionadas à consciência de responsabilidade social. Para Shaw e Newholm (2002), seriam motivações centradas em interesses pessoais, em posturas altruístas e em princípios éticos. McDonald, Oates, Young et al. (2006) consideram que a busca pela vida simples teria relação com o desejo de crescimento individual.

A forma como os indivíduos adotam a simplicidade voluntária é variada (BEKIN; CARRIGAN; SZMIGIN, 2007). Zavestoski (2002) analisou motivações dos adeptos a partir de publicações existentes, dividindo-as por épocas (1973-1994 e 1995-1998), para evidenciar mudanças ao longo do tempo (Tabela 1).

Tabela 1: Motivações para a simplicidade voluntária

\begin{tabular}{lcccc}
\hline Período & $\begin{array}{c}\text { Espiritualidade } \\
\text { Aspectos Religiosos }\end{array}$ & $\begin{array}{c}\text { Virtudes da } \\
\text { Simplicidade }\end{array}$ & $\begin{array}{c}\text { Redução do Estresse } \\
\text { Aumento da Realização }\end{array}$ & $\begin{array}{c}\text { Estratégias para } \\
\text { simplificar }\end{array}$ \\
\hline $1973-1994$ & $38 \%(10)$ & $50 \%(13)$ & $0 \%(0)$ & $11,5 \%(3)$ \\
$1995-1998$ & $25 \%(8)$ & $21,9 \%(7)$ & $28,1 \%(9)$ & $25 \%(8)$ \\
Total & $31 \%(18)$ & $34,5 \%(20)$ & $15,5 \%(9)$ & $19 \%(11)$ \\
\hline
\end{tabular}

Fonte: Zavestoski (2002)

No período de 1973-1994, as publicações enfatizavam as virtudes de se adotar vida simples e relacionavam religiões com a simplicidade. Entre 1995-1998, passaram a enfatizar a redução do estresse e o aumento da realização, e as estratégias para simplificar a vida (como um passo-a-passo para a simplicidade). As publicações dos últimos anos consideram que a decisão de ser simples parece ser uma forma de reduzir estresse e buscar felicidade, contentamento, realização e satisfação.

No passado, muitos buscavam a simplicidade em decorrência de crises financeiras vividas. Hoje, a busca passa a ser relacionada a crises pessoais (e não financeiras) ou a questionamento existencial, sendo uma motivação individual (ZAVESTOSKI, 2002).

Craig-Lees e Hill (2002) conduziram um estudo qualitativo na Austrália, investigando posses dos adeptos da simplicidade voluntária, seu estilo de vida e hábitos de compra. Os entrevistados tinham alta renda e idades entre 40 e 55 anos. Os resultados apontaram três principais motivações para se tornar um praticante da simplicidade voluntária: preocupação com o meio ambiente, espiritualidade e orientação pessoal. 


\section{TRANSFORMAÇÕES INDIVIDUAIS COM A ADOÇÃO DA SIMPLICIDADE VOLUNTÁRIA}

A maior parte dos estudos sobre o tema relata mudanças que os adeptos da simplicidade voluntária realizaram em suas vidas. Shama (1981), por exemplo, identificou diferenças no consumo entre adeptos da simplicidade voluntária e os que não a adotaram (Quadro 1).

\section{Quadro 1: Comparação entre consumidores}

\begin{tabular}{|l|l|}
\hline \multicolumn{1}{|c|}{ Consumidores } & \multicolumn{1}{c|}{ Consumidores da vida simples } \\
\hline Produtos maiores & Produtos menores ('menor é bonito') \\
\hline Muitos produtos & Menos produtos ('menos é melhor') \\
\hline Produtos de luxo & Produtos simples e funcionais, porém de qualidade \\
\hline Produtos centrados em si mesmo & Produtos 'faça você mesmo' \\
\hline Grandes lojas para comprar & Lojas menores, pessoais \\
\hline Lojas tradicionais para comprar & Lojas inovadoras (ex: 'mercado de pulga'; vendedor de rua) \\
\hline TV e promoção de mídia de massa & Rádio ou promoção informativa, impressa \\
\hline
\end{tabular}

Fonte: Shama (1981, p. 128)

Johnston e Burton (2003) também compararam o que buscavam consumidores em geral e os que adotaram vida mais simples (Quadro 2).

Quadro 2: Consumo na vida simples

\begin{tabular}{|l|l|}
\hline \multicolumn{1}{|c|}{ Consumidores em geral } & \multicolumn{1}{c|}{ Indivíduos que vivem uma vida simples } \\
\hline Buscam mais bens materiais & Preferem ter menos posse \\
\hline Buscam ganhar mais & Buscam trabalho (pago) reduzido \\
\hline Querem consumir mais & Buscam consumir menos \\
\hline Buscam conveniência & Querem bens duráveis, reaproveitáveis, que são 'amigos' do planeta \\
\hline Buscam comprar o que querem & Querem pouco, compram pouco \\
\hline
\end{tabular}

Fonte: Johnston e Burton (2003, p. 22)

Etzioni (1998) concluiu que o processo da adoção da simplicidade voluntária é composto por três estágios, ou níveis. No nível moderado, que denominou de downshifters, o indivíduo continua a consumir sem mudanças drásticas, mas não compra produtos considerados como luxuosos. Esse grupo é o menos radical nas mudanças, reduzindo o consumo em certa medida, mas continuando a ter alto padrão de vida. Podem, entretanto, vestir-se de maneira mais simples e ter carros menos modernos (ETZIONI, 1998).

O nível intermediário (strong simplifiers) é composto por pessoas que tinham uma atividade profissional que consideravam estressante e, embora bem remuneradas, deixaram seus empregos para viver com menos, mas felizes e de forma mais simples. Etzioni (1998) citou casos de pessoas em cargos executivos que os abandonaram e passaram a viver de economias, usando o tempo de que passaram a dispor para escrever ou fazer trabalhos voluntários. Neste nível, encontram-se indivíduos que resolvem aposentar-se cedo, para ter mais tempo para o lazer, e quem busca emprego em período parcial ou trabalhando em casa. 
Etzioni (1998) considerou como o nível mais elevado da simplificação a holística, quando é vivenciada em sua forma integral. Seus praticantes geralmente preferem morar em cidades pequenas ou em áreas rurais.

Elgin (2000) também descreveu mudanças de comportamento decorrentes da adoção da vida simples: desfrutar de mais tempo para a família e com amigos; exercitar-se ou praticar esportes; desenvolverse emocional, mental e espiritualmente; estar em contato com a natureza; ter compaixão com pessoas que passam por dificuldades; reduzir o nível de consumo, valorizando o que é funcional e durável; ter alimentação saudável e natural; boicotar produtos e serviços de empresas que tenham práticas consideradas antiéticas; reciclar produtos, ao invés de descartá-los; ter vida autossuficiente; envolver-se em causas a favor do meio ambiente e da proteção dos animais; mudar meio de transporte, dando preferência a transporte público, bicicleta ou carros mais eficientes.

McDonald, Oates, Young et al. (2006) citaram a redução do consumo e o consumo sustentável como formas para poupar recursos e minimizar impacto ambiental e classificaram os adeptos da simplicidade voluntária em iniciantes e os que já incorporaram seus princípios. Os iniciantes (beginner voluntary simplicity) têm alguns hábitos, que são comportamentos iniciais, em prol do meio ambiente, como a reciclagem. Podem ser simplificadores aprendizes, simplificadores parciais ou simplificadores acidentais.

Os aprendizes estão passando por transformação para se tornarem, no futuro, adeptos da simplicidade voluntária. Pessoas que adotaram algumas ações da simplicidade voluntária, como levar os filhos para a escola caminhando, mas utilizar o automóvel para ir ao trabalho, estão na simplificação parcial. São mais inclinados a comprar itens cuja produção respeite o meio ambiente e seja considerada ética. Os que adotaram a vida simples como consequência de restrições financeiras praticam a simplificação acidental. Porém, McDonald, Oates, Young et al. (2006) destacaram que, por não envolver livre escolha, esta última categoria não pode ser considerada como simplicidade voluntária.

O Quadro 3 resume as principais mudanças do indivíduo, ao optar pela vida simples.

Quadro 3: Mudanças para adotar a vida simples

\begin{tabular}{|l|l|}
\hline \multicolumn{1}{|c|}{ Principais mudanças } & \multicolumn{1}{c|}{ Autores } \\
\hline - Redução do consumo (eliminação de bens supérfluos) & Craig-Lees e Hill (2002); Shaw e \\
- Produtos funcionais e de qualidade (podem ter preço alto) & Newholm (2002); Huneke (2005); \\
- Não valorizam marcas só por serem famosas & Bekin, Carrigan e Szmigin (2007); \\
-Consumo verde, responsável e comércio local & Oates, McDonald, Alevizou et al. \\
- Plantação de alguns alimentos & (2008); Shaw e Moraes (2009); \\
- Alimentos orgânicos; Vegetarianismo & Albisson e Perera (2009); Abdala e \\
- Produtos usados ou emprestados & Mocellin (2010); Ballantine e Creery \\
- Reciclagem & (2010); Alexander e Ussher (2011). \\
- Economia de energia e água & \\
-Carona solidária e uso de bicicleta & \\
-Trabalho com significado positivo, que traga satisfação & \\
- Gastar menos tempo trabalhando & \\
\hline
\end{tabular}

Fonte: Elaborado com base na revisão da literatura 
Poucos estudos investigaram benefícios e pontos negativos da adoção da simplicidade voluntária. Alguns enfatizam mais os benefícios (ETZIONI, 1998; CRAIG-LEES; HILL, 2002; HUNEKE, 2005; ALEXANDER; USSHER, 2011; ELGIN, 2012), que podem ser individuais (como felicidade e liberdade) e coletivos (como preservação ambiental). Sobre aspectos negativos da adoção da simplicidade voluntária, Shi (1997) menciona a dificuldade em abrir mão da posse de bens materiais.

\section{MÉTODO}

O grupo pesquisado constitui uma comunidade virtual na rede social Facebook, dedicada ao tema simplicidade voluntária. Reúne indivíduos de todo o Brasil e somente membros do grupo podem interagir. $\mathrm{O}$ método envolveu netnografia, que permite investigar comunidades virtuais, explorando-se com mais frequência dados provenientes de debates em fóruns virtuais (KOZINETS, 1998).

Além da participação no grupo durante dez meses, acompanhando-se as mensagens trocadas entre os participantes, foram conduzidas treze entrevistas em profundidade, guiadas por roteiro semiestruturado, com membros do grupo que se ofereceram como voluntários respondendo a uma mensagem de recrutamento publicada no grupo e autorizada pela moderadora, que se prontificou a ser uma das entrevistadas.

A maioria (dez pessoas) dos membros que responderam a mensagem de recrutamento interagia muito no grupo, compartilhando informações. Houve três voluntários que eram passivos, apenas leitores do que era discutido. Seis membros moravam em São Paulo, três em Minas Gerais e uma, a moderadora, residia na cidade do Rio de Janeiro. Três entrevistados moravam em cidades distantes, com acesso difícil (uma no litoral de São Paulo, outra no interior do Paraná e o terceiro, apesar de ser de São Paulo, estava viajando pela Austrália). Por questões de praticidade e de custo, optou-se por realizar essas três entrevistas por meio de Skype. As demais foram conduzidas pessoalmente, nas cidades de residência de cada entrevistado.

A coleta de dados foi feita por meio de leitura dos posts publicados no grupo do Facebook e a partir das entrevistas, que foram gravadas com o consentimento dos entrevistados e posteriormente transcritas. A Figura 1 apresenta o fluxo de coleta e tratamento dos dados, adaptado de Rubin e Rubin (2004).

Figura 1: Etapas de coleta e tratamento dos dados

\begin{tabular}{|c|c|c|c|}
\hline $\begin{array}{c}\text { Entrada no grupo } \\
\text { virtual Simplicidade } \\
\text { Voluntária }\end{array}$ & $\begin{array}{c}\text { Acompanhamento } \\
\text { dos debates do } \\
\text { grupo }\end{array}$ & $\begin{array}{c}\text { Elaboração do roteiro } \\
\text { semiestruturado de } \\
\text { entrevista }\end{array}$ & $\begin{array}{c}\text { Autorização para recrutar } \\
\text { entrevistados no grupo } \\
\text { virtual }\end{array}$ \\
\hline $\begin{array}{l}\text { Redação dos } \\
\text { resultados } \\
\text { encontrados }\end{array}$ & $\begin{array}{c}\text { Análise das } \\
\text { entrevistas e dos } \\
\text { debates do grupo }\end{array}$ & $\begin{array}{l}\text { Agendamento e } \\
\text { realização das } \\
\text { entrevistas }\end{array}$ & $\begin{array}{c}\text { Divulgação de mensagem } \\
\text { de recrutamento dos } \\
\text { entrevistados }\end{array}$ \\
\hline
\end{tabular}

Fonte: Adaptado de Rubin e Rubin (2004) 


\section{ANÁLISE DOS RESULTADOS}

\section{Perfil dos entrevistados}

Treze pessoas, quatro homens e nove mulheres, foram entrevistadas, com idades entre 28 e 60 anos, todas classificadas nas classes socioeconômicas A e B (ABEP, 2015). Não declararam ter restrições financeiras e residiam em imóveis próprios ou alugados. Dois entrevistados possuem outros imóveis, que alugam para aumentar a renda. Todos praticavam a simplicidade voluntária havia pelo menos um ano, porém muitos a adotaram há mais tempo. Para manter o anonimato, os nomes aqui apresentados são fictícios.

\section{Motivações para a Adoção}

\section{Insatisfação no Trabalho}

A literatura menciona como importante motivação o desejo dos consumidores de reduzir o estresse, muitas vezes ligado ao trabalho que têm (CRAIG-LEES; HILL, 2002; ZAVESTOSKI, 2002; HUNEKE, 2005; ETZIONI, 1998; OATES, MCDONALD, ALEVIZOU et al., 2008), levando o indivíduo a optar pela simplicidade voluntária. Os entrevistados e outros membros do grupo relataram essa razão para a adoção. Sete entrevistados estavam insatisfeitos no trabalho e resolveram mudar de profissão, ou, se ainda não mudaram, têm planos futuros de buscar um trabalho que proporcione prazer e felicidade: "Porque eu acho que a demanda, assim o que me exigia o jornalismo, hoje quando eu penso (...). Trabalhar com isso não é uma coisa que me dava prazer. Não era prazerosa para mim (...). Depois de um tempo que eu fui entender que aquilo não me fazia bem". (Marlena).

Mensagens trocadas no grupo também revelam que os membros discutem bastante sobre escolhas profissionais e sobre como a simplicidade voluntária afeta suas trajetórias de carreira. A importância de ter um trabalho prazeroso está frequentemente presente nos debates, inclusive em ilustrações que eles compartilham (Figura 2).

Figura 2: Prazer no trabalho
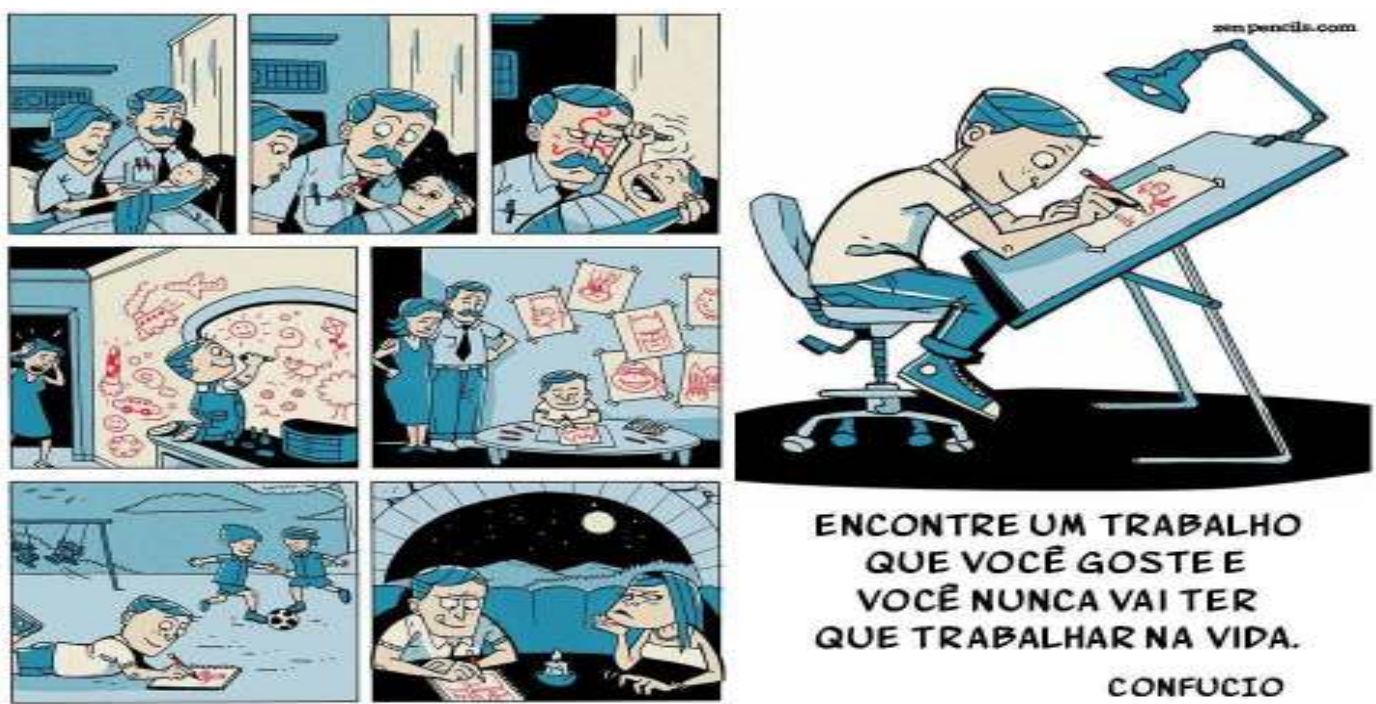

Fonte: Página do Facebook de "Inteligente Vida" CONFUCIO 


\section{Insatisfação com exagero no consumo}

Tanto os entrevistados como outros membros do grupo revelaram frustrações e insatisfações que sentiam à época em que eram consumistas, corroborando descobertas anteriores (CSIKSZENTMIHALYI, 1999; AHUVIA, 2008). Adquiriam bens e tinham satisfação na hora da compra, mas que rapidamente dava lugar a outro desejo de consumo: "Eu acho que passou por um questionamento, porque a gente está nesse círculo vicioso de você compra uma coisa, eu quero determinada coisa, é um sonho de consumo para mim, quando você consegue a satisfação advinda daquilo, dura pouco" (Thalita).

Mensagens trocadas mostraram insatisfação decorrente do consumo exagerado, que levou os consumidores a adotar vida simples: "O mais incrível é que milhões de pessoas ao redor do mundo vivem entorpecidas na ilusão de que comprar é viver, enfiadas em engarrafamentos, endividadas, gordas e doentes e acham que isso seja NORMAL" (frase de mensagem no grupo). Três entrevistadas relataram que decidiram adotar a simplicidade voluntária por estarem insatisfeitas com o consumo exagerado. Ao o reduzirem, eliminaram frustrações recorrentes.

As mensagens trocadas sugerem que a percepção do grupo é de que as pessoas dedicam a vida a trabalhar em excesso para ter dinheiro e poder acumular bens, tornando-se escravas do acúmulo das posses materiais e de sua manutenção, sem tempo livre para divertimento e prazer. Houve relatos que associavam a felicidade que o consumo de bens prometia à falsidade e à ilusão. Consumo traria apenas felicidade ilusória, fugaz. Ao tomarem consciência, decidiram reduzir o consumo de bens, passando a ter mais tempo para o que efetivamente proporcionava prazer.

Percebendo que não haveria necessidade de se trabalhar tanto se não houver necessidade de acumular bens materiais, oito entrevistados resolveram buscar trabalho que lhes desse prazer, mesmo com rendimentos menores. Abdicaram de ambição profissional, passaram a trabalhar naquilo de que gostavam e o dinheiro que ganham é usado para atividades prazerosas.

\section{Vida espiritual e religião}

Alguns membros do grupo relataram que a vida espiritual (não relacionada à religião) os fez optar pela vida simples. Para eles, é importante a vida espiritual, em detrimento da puramente materialista: "As minhas aspirações espiritualistas. Então o essencial não está na matéria" (Beth). A religião também teve papel importante na vida de alguns membros do grupo, que passavam por momentos de incerteza e insatisfação, trazendo respostas para seus questionamentos, sendo grande impulsionadora na mudança de vida. Em alguns relatos, foram orientados pela religião para a prática da vida simples, onde a abundância não é necessária para a felicidade.

Outros relataram a necessidade de dar sentido à vida. Não estavam encontrando sentido na maneira como viviam ou trabalhavam e viram a simplicidade voluntária como uma solução para viver melhor:

Aí comecei a ver que a vida não tinha muito sentido dessa forma: a gente trabalha que nem um condenado para ter umas férias de sei lá, vinte dias, trinta dias, e achar que a vida vale a pena. Para mim eu acho que isso não vale a pena. Eu acho que a 
gente tem que todo dia acordar e querer viver aquele dia. Quando eu estava trabalhando na agência eu acordava e queria que o dia acabasse o quanto antes, isso para mim não era vida. Então eu acho que a partir daí eu comecei a procurar viver de uma forma diferente (José).

Com a vida simples, passaram a ter contato com amigos e família, sem pressões de tempo no dia a dia, e a valorizar mais questões espiritualistas, no lugar de ocuparem-se apenas com aspectos eminentemente de natureza materialista.

Essas questões também estão presentes na literatura (ELGIN; MITCHELL, 1977b; CRAIG-LEES; HILL, 2002; ZAVESTOSKI, 2002).

\section{Mais tempo para o lazer}

Os entrevistados ressaltam a importância dos relacionamentos pessoais, de ter amigos e familiares por perto, de prezar laços de afeto. Tinham estilo de vida que exigia excesso de trabalho e alto consumo. Resolveram adotar a simplicidade voluntária para ter mais tempo para se dedicarem a relacionamentos, a si próprios e a atividades prazerosas: "E assim, depois que minhas filhas nasceram que entrei nessa, preciso ter mais tempo, inclusive para estar com elas" (Paulo). Os membros do grupo trocam muitas informações sobre a importância de dar atenção aos filhos e passar para eles os princípios da simplicidade voluntária. A Figura 3, uma imagem compartilhada no grupo de discussão do Facebook, ilustra a valorização dos relacionamentos (neste caso com os filhos).

Figura 3: Relacionamentos com filhos

\section{Os melhores presentes} que podemos dar aos nossos filhos são grâtis

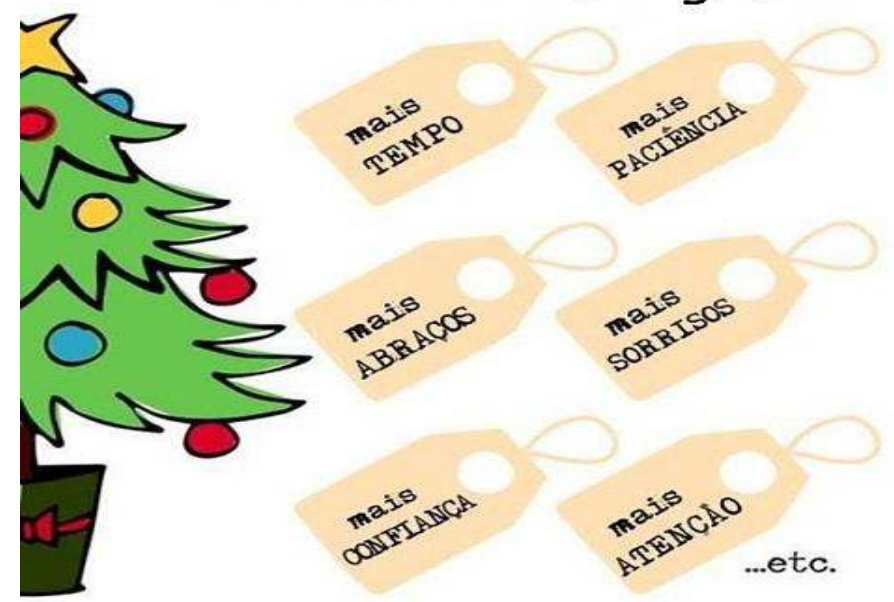

Fonte: Página do Facebook de "Humor Inteligente" 
Além disso, valorizam muito as atividades que dão prazer e divertimento. Esses achados estão de acordo com a literatura da simplicidade voluntária, que menciona amplamente a necessidade de mais tempo para o lazer e para se relacionar (ETZIONI, 1998; HUNEKE, 2005; ALEXANDER; USSHER, 2011).

\section{Resgate de valores familiares}

Alguns entrevistados nasceram em famílias humildes (pobres ou rurais), porém, ao longo da vida, passaram a viver com trabalho em excesso e/ou compras de bens. A entrevistada Jane relatou que chegou a ter vários pares de sapatos. Esse consumo exagerado Ihes trouxe insatisfação constante, sentiram necessidade de resgatar os valores familiares de simplicidade. Eram felizes àquela época e perceberam que não precisavam de muitos bens materiais para alcançar a felicidade: "Isso aí quase que é resgate mesmo, porque fui criada com meus avós (...) que tinham horta em casa, a comida era feita com tudo do quintal". (Rosa).

Esses resultados corroboram a literatura (LEONARD-BARTON, 1981), que menciona a influência da criação da família na adoção da vida simples.

\section{Libertação da pressão da sociedade}

Alguns entrevistados e membros do grupo adotaram a simplicidade voluntária por se sentirem dependentes da pressão social de ter que consumir. Queriam vida com mais liberdade, sem ser conduzidos por ambições profissionais, sem ter que se vestir da forma como a sociedade determina. Para eles, a simplicidade voluntária significava a verdadeira liberdade de viver: "Só não quero ter que carregar o fardo de estar sempre tendo que fazer isso ou aquilo, ou usando isso ou aquilo, em função do que as pessoas, do que se intitulou como moda ou como viável ou como que está na onda, sabe. Isso eu não quero" (Rosa).

Entrevistados e membros do grupo também gostam de se sentir mais independentes, não só em relação ao padrão que a sociedade impõe, mas também em relação ao consumo de outros bens. Rosa e Paulo têm plantações em casa e quatro entrevistados fazem, eles mesmos, alguns serviços ou produtos (costura, pintura).

A literatura também relata essa necessidade de independência dos adeptos da vida simples, que tentam ter algum nível de autossuficiência e maior liberdade (ELGIN; MITCHELL, 1977b; BEKIN; CARRIGAN; SZMIGIN, 2007).

\section{Motivações para a vida simples: Resultados e Literatura}

Diversos estudos (ELGIN; MITCHELL, 1977b; CRAIG-LEES; HILL, 2002; SHAW; NEWHOLM, 2002; OATES, MCDONALD, ALEVIZOU et al., 2008) relatam que motivações para adotar a simplicidade voluntária são tanto de natureza pessoal (como insatisfação no trabalho) quanto de natureza coletiva (como a preocupação com o meio ambiente). Há inclusive estudos que enfatizam motivações ligadas à sociedade e ao meio ambiente, como o livro de Elgin (2012). 
Porém, os resultados aqui encontrados apontaram apenas motivações relacionadas a interesses pessoais, achado interessante para os estudos da simplicidade voluntária, que abre espaço para investigações futuras.

\section{Mudanças}

As mudanças ocorridas na vida dos entrevistados e de outros membros do grupo virtual foram classificadas com base em achados da literatura.

- Vida profissional: praticantes da vida simples reduzem carga horária de trabalho e buscam empregos que deem prazer, não priorizando ganhos financeiros. Os resultados encontrados corroboram com a literatura (ETZIONI, 1998).

- Moradia: adeptos da simplicidade voluntária reduzem complexidade de moradia e podem mudar-se para regiões rurais ou para o interior: "A casa é muito grande para mim, eu vou querer por quê? Por que era no centro? Por que eu vou querer uma casa tão grande se eu sou sozinha?" (Clarice). Os resultados corroboram com os achados da literatura (ETZIONI, 1998; BEKIN; CARRIGAN; SZMIGIN, 2007).

- Transporte: adeptos da vida simples priorizam o uso de transporte público, da bicicleta e o caminhar. Quando possuem automóveis, não se preocupam com que seja um modelo moderno, pois é utilizado somente por razões utilitárias: "Meu carro tem dez anos. Se eu pudesse abrir mão totalmente, eu até abriria. Mas, assim, eu utilizo vez ou outra o carro, já usei mais, com a simplicidade eu consegui reduzir o uso" (Rubem). Os resultados encontrados estão de acordo com a literatura (SHAW; NEWHOLM, 2002; HUNEKE, 2005; ALEXANDER; USSHER, 2011).

- Alimentação: passa a ser baseada em produtos naturais, menos industrializados. Alguns plantam alimentos que consomem. Confirmam-se achados mencionados na literatura (BEKIN; CARRIGAN; SZMIGIN, 2007).

- Consumo de bens: é um dos assuntos mais abordados na literatura sobre o tema, mencionando a redução drástica do consumo de produtos, comprando somente o que julgam necessário e considerando questões utilitárias. Os resultados encontrados estão de acordo com a literatura. As principais mudanças em relação ao consumo de bens foram:

- Redução do consumo de bens em geral, principalmente roupas, sapatos, acessórios, objetos decorativos, produtos tecnológicos, remédios, produtos de limpeza e produtos de beleza.

- Preferência por produtos com qualidade e longa durabilidade, podendo ser mais caros e não necessariamente de marcas famosas.

- Preferência por produtos que não agridam o meio ambiente e por marcas conhecidas pela ética e responsabilidade social. Boicotam marcas social ou ambientalmente incorretas.

- Compra de alguns produtos usados, como roupas, livros e acessórios. Compras realizadas em brechó, bazares e sebos.

- Uso de produtos até o fim da vida útil (não o trocam só porque foi lançado modelo novo ou entrou na moda). Tentam consertá-lo ao invés de comprar um novo.

- Preferência por produtos feitos à mão e vendidos localmente. 
- Produtos mais simples, como roupas, e redução da complexidade tecnológica.

- Recebimento de doações (alguns já receberam doações de roupas de pessoas conhecidas).

- Descarte: como mencionado na literatura (HUNEKE, 2005), os adeptos da vida simples se preocupam com o lixo que geram (reduzindo-o) e com o descarte de produtos (reaproveitando, reciclando e doando): "Alimentação a gente nunca descarta, sempre faço a quantidade certa para mim e para ele (o marido)". (Catarina).

- Organização pessoal: reduzem o acúmulo de bens e a desordem, sendo vigilantes para não acumular bens: "Casas mais simples, sem tralha, são mais fáceis de manter (...). Aprendi que tralha nunca é organizável, temos é que nos desvencilhar dela!" (Frase compartilhada no grupo do Facebook). Diversos autores mencionaram essa preocupação em não acumular (BALLANTINE; CREERY, 2010).

- Valorização de experiências: preferem estar em contato com a natureza, ter tempo para relacionamento com amigos e familiares, viagens, atividades que thes dão prazer. Apesar de ser um assunto amplamente discutido na literatura, os estudos não mencionam que a busca por experiências, muitas vezes, está relacionada ao consumo de serviços. Este é um achado relevante deste trabalho: o grupo ressaltou a valorização do consumo de serviços. As experiências estavam relacionadas tanto a atividades gratuitas, como a atividades que demandavam gastos financeiros, como viagens, contato com a natureza, atividades culturais, cursos, contato com familiares e amigos, momentos de lazer e prática de esportes.

- Consciência ambiental e social: amplamente abordado na literatura, principalmente como motivação para adotar a simplicidade voluntária. Porém, no presente estudo, os adeptos pareceram não adotar vida simples por preocupações de natureza ambiental ou social. Entretanto, ao adotar a simplicidade voluntária, passaram a se preocupar com essas questões e adotar essa postura.

\section{Benefícios e Pontos negativos}

A simplicidade voluntária parece resultar em consequências positivas para seus praticantes. Benefícios pessoais relatados envolveram felicidade, tranquilidade e maior qualidade de vida (relacionados à vida mais prazerosa), saúde (devido à alimentação saudável e redução de jornada de trabalho), economia (redução de gastos desnecessários), economia de tempo gasto com trabalho excessivo e compra de bens e liberdade (não se submeter à pressão social). Os membros do grupo discutem, de forma recorrente, os benefícios que a vida simples traz.

Estudos existentes sobre simplicidade voluntária mencionam benefícios da vida simples, porém abordam apenas superficialmente os aspectos negativos dea adoção, embora haja referências à dificuldade de desfazer-se de bens materiais (SHI, 1997). O grupo investigado relatou a dificuldade inicial de selecionar os bens que seriam descartados. Entretanto, o principal ponto negativo apontado é o isolamento de alguns conhecidos, devido a diferenças de criação e forma de viver. Este isolamento não é de natureza física: são incompreendidos pelas pessoas ao seu redor, criticados e questionados sobre as razões para ser simples.

Também relatam que as pessoas que não os conhecem confundem a vida que levam com voto de pobreza ou mesquinharia. A simplicidade voluntária, na visão do grupo, é "remar contra a maré", "estar na contramão de tudo": "Olha, ponto negativo eu acho que seria você se afastar um pouco dos amigos e da 
família (...). Não que tenha conflito, mas a convivência acaba tendo um afastamento sim. Isso não tem como negar" (José).

A literatura sobre simplicidade voluntária não aborda o isolamento dos adeptos, embora seja assunto recorrente no discurso do grupo. Em estudos sobre solidão, Weiss (1973) considera duas dimensões: a solidão emocional e o isolamento social. A primeira é associada à perda de um ente querido (familiares, amigos), que faz com que a pessoa se sinta emocionalmente sozinha. $O$ isolamento social ocorre quando um indivíduo não se sente integrado a alguma rede de relacionamentos, excluído de alguma comunidade. Os entrevistados e outros membros do grupo virtual relataram sofrer de isolamento social, por se distanciarem de pessoas conhecidas, familiares e amigos, ou por serem incompreendidos. Por outro lado, relatam que a participação no grupo virtual é importante para conseguirem seguir em frente, pois o grupo dá apoio, troca informação e, muitas vezes, cria novos laços de amizade.

Os resultados apontaram para interesses pessoais como principal motivação para adesão à simplicidade voluntária. Esse achado é importante, já que a literatura menciona amplamente a motivação de preservação do meio ambiente, o que não surgiu nem nas entrevistas, nem nas mensagens do grupo. Pode ser que essa seja uma especificidade do grupo, ou talvez característica relacionada à cultura, já que estudos existentes foram conduzidos em outros países.

\section{Proposições}

Algumas proposições podem ser apresentadas, a partir dos resultados obtidos:

\section{Proposição 1- As motivações para a adoção da simplicidade voluntária no Brasil tendem a ser de natureza pessoal.}

A literatura aponta diversas alterações decorrentes da adoção da simplicidade voluntária: redução do consumo de bens, mudanças na vida profissional, moradia e meios de transporte utilizados, alimentação mais saudável, preocupações com descarte de produtos, mais organização pessoal, valorização de experiências, consciência ambiental e social e algum nível de autossuficiência (ETZIONI, 1998; CRAIG-LEES; HILL, 2002; HUNEKE, 2005; SHAW; MORAES, 2009).

Esse é o tópico mais investigado na literatura - mudanças que adeptos da vida simples fazem para colocá-la em prática. Os resultados obtidos confirmam achados anteriores. Ao viver uma vida mais simples, parece que os adeptos têm mais prazer, como se para eles, prazer não estivesse associado a consumo de bens materiais, mas sim a não depender da posse de bens.

A literatura menciona a importância de experiências prazerosas no consumo de produtos (HOLBROOK, 2000). Porém, para o grupo investigado, esse tipo de consumo não oferece prazer. Eles consideram ilusão achar que o acúmulo de bens materiais traz felicidade ("Sonho de consumo uma bolsa... é muita pobreza..." - Frase compartilhada no grupo virtual). Por outro lado, o hedonismo está associado a não consumir, é o efeito contrário. Apesar de minimizarem a posse de bens materiais, sentem-se felizes e orgulhosos. Não acumular produtos parece dar prazer. Para eles, o prazer advém do consumo de serviços (viagens, restaurantes, atividades culturais, eventos, cursos), experiências prazerosas, momentos que ficam 
gravados indelevelmente na memória. Os membros do grupo foram enfáticos ao declarar que valorizam o consumo de serviços. Esse achado, ignorado na literatura, abre caminho para novas linhas de pesquisa sobre simplicidade voluntária, para investigar com mais profundidade o hedonismo, relacionado a não consumir bens materiais e ligado ao consumo de serviços.

\section{Proposição 2- Ao adotar a simplicidade voluntária, apesar de reduzirem o consumo de bens, os indivíduos tendem a continuar consumindo serviços.}

Estes achados abrem caminho para novas linhas de pesquisa: identificar produtos considerados supérfluos; identificar serviços considerados supérfluos; identificar serviços mais consumidos; a importância do preço em serviços consumidos.

O consumo está relacionado a significados, a questões simbólicas e para evidenciar uma identidade (LEVY, 1959; BAUDRILLARD, 2008). Entretanto, parece que o grupo praticante da simplicidade voluntária não busca significados por meio do consumo. Enquanto autores defendem a compra de produtos para que um indivíduo se distinga na sociedade (BOURDIEU, 2004), os adeptos da simplicidade voluntária desse grupo não declaram utilizar o consumo como instrumento de diferenciação. Na realidade, desprezam essa razão para consumir e se consideram diferentes porque são adeptos da simplicidade voluntária: a distinção se dá pelo não consumo, ao invés de ser através do consumo. Parece que os adeptos da vida simples se veem de forma diferenciada do restante da sociedade.

Apesar de declararem ter adotado a vida simples por motivos pessoais, ao adotarem a simplicidade voluntária os membros do grupo passaram a se preocupar mais com o meio ambiente e com problemas sociais. Mesmo que as motivações para simplificar suas vidas sejam relacionadas a interesses pessoais, passaram a se preocupar com o coletivo. A descoberta é importante, já que a literatura considera que as motivações são tanto individuais como coletivas, abrindo caminho para novas investigações, talvez relacionadas a influências culturais sobre motivações para a adoção.

\section{Proposição 3- Ao adotarem a simplicidade voluntária no Brasil, os indivíduos incorporam valores sociais e ambientais.}

Os resultados revelaram benefícios pessoais e coletivos advindos da adoção da simplicidade voluntária. Como benefícios pessoais, mais felicidade, mais liberdade, mais tranquilidade, melhor qualidade de vida, saúde melhor e economia, financeira e de tempo. Os benefícios coletivos estão ligados à preservação do meio ambiente e às contribuições que a simplicidade voluntária traz para a sociedade, corroborando estudos anteriores.

Como pontos negativos, o grupo destacou a dificuldade de selecionar que bens materiais deverão ser descartados. Entretanto, ficou evidente que, ao tornarem-se mais organizados, as pessoas passam a superar essa dificuldade inicial para se adequar ao novo estilo de vida.

O estudo identificou outro ponto negativo, apontado de forma recorrente pelos entrevistados e por outros membros do grupo virtual: o afastamento de amigos, familiares e outros indivíduos. Fica evidente, a partir das comunicações no grupo e mais claramente das entrevistas, que se sentem incompreendidos pelas 
pessoas que as rodeiam, que não entendem os motivos pelos quais adotaram a simplicidade voluntária, confundindo a escolha feita com mesquinharia, com mera acomodação ou, principalmente, como consequência de dificuldades financeiras.

O grupo expressa que há pressão social para que mantenham um padrão de vida considerado como "compatível" com o de seu grupo social. O isolamento decorrente do não conformismo com os padrões da sociedade (WEISS, 1973) é ignorado pela literatura sobre a simplicidade voluntária, sendo, portanto, achado relevante deste estudo, já que, de forma recorrente, os entrevistados diziam-se isolados da sociedade, ainda seja uma percepção apenas. Abre-se caminho para novas linhas de estudo: até que ponto o isolamento social é visto como um aspecto negativo? Há indivíduos que já desistiram da simplicidade voluntária por não se sentirem inseridos nos padrões sociais? Há quem pense em se tornar adeptos da vida simples, receie a incompreensão de seus grupos sociais?

Proposição 4.1- Parece haver um conjunto de barreiras sociais que podem impedir as pessoas de adotarem a simplicidade voluntária.

Proposição 4.2 - Indivíduos podem ser levados a abrir mão de relacionamentos com grupos sociais e familiares para continuarem adeptos da simplicidade voluntária.

Em razão dessa incompreensão, muitos se apoiam no grupo virtual, pois sabem que, além de fonte de informações e debates, ali serão compreendidos quando passam por momentos difíceis em sua vida pessoal. Algumas amizades já se tornaram presenciais, o que incentiva os participantes a organizar encontros e estabelecer laços de amizades mais fortes.

Proposição 5- Ao estabelecer novos laços de amizade com indivíduos que adotam a simplicidade voluntária, as barreiras sociais que podem impedir as pessoas de adotá-la são minimizadas.

\section{CONSIDERAÇÕES FINAIS}

A simplicidade voluntária é tema pouco explorado na literatura. Muitos estudos são de natureza teórica, havendo poucas pesquisas empíricas. O presente trabalho teve o objetivo de investigar motivações para ser adepto da simplicidade voluntária e diversos impactos que sua adoção causa na vida dos que a praticam. Para tal, foram acompanhadas as mensagens trocadas por membros de um grupo virtual do Facebook e conduzidas entrevistas em profundidade com alguns deles.

As motivações para a adoção da simplicidade voluntária parecem ser de natureza pessoal, não sendo consequência de restrições financeiras, nem motivadas por crenças religiosas. Como aspecto curioso, os relatos dos entrevistados sugerem que eles tendem a incorporar valores sociais e ambientais que antes não tinham. 
Conviver com algumas consequências da escolha pela simplicidade pode trazer dificuldades na vida. Barreiras sociais podem impedir a adoção da simplicidade voluntária ou levar alguns ao arrependimento. Alguns praticantes podem ser levados a abrir mão de relacionamentos com amigos e parentes que os criticam, e deles se afastam, o que tem potencial para criar sentimentos de isolamento social. Quando estabelecem laços de amizade com outros adotantes, seja por meio de relações presenciais, seja ao participar de grupos de discussão em redes sociais, sentem-se acolhidos e pertencentes, partilhando livremente experiências e descobertas.

Os achados deste estudo trazem importantes contribuições para o conhecimento sobre a simplicidade voluntária, tema pouco explorado na literatura sobre o comportamento do consumidor. Ademais, sob o ponto de vista gerencial, é relevante estudar a simplicidade voluntária no Brasil, já que o fenômeno tem potencial para provocar mudanças significativas no comportamento de compra e no uso de algumas categorias de produtos e serviços, caso sua adoção venha a ser ampliada. Percebe-se, por exemplo, que embora o consumo de bens seja reduzido, especialmente em algumas categorias, o consumo de serviços é mantido ou ampliado, especialmente o de cursos, de viagens e de lazer.

Os resultados obtidos, bem como proposições deles decorrentes, sugerem alguns caminhos para futuras pesquisas. Algumas questões podem ser propostas, visando alargar os horizontes do que hoje se conhece sobre o tema. Adeptos da simplicidade voluntária tendem a se unir e a formar grupos de amizade, que possam propagar sua forma de viver? A participação em grupos virtuais sobre simplicidade voluntária seria uma forma de compensação das perdas de relacionamentos com amigos e familiares, que decorrem das escolhas feitas pelos adotantes, assim minimizando possíveis sensações de isolamento social? 


\section{REFERÊNCIAS}

ABDALA, P. R. Z.; MOCELLIN, G. M. P. Ecovillages and Permaculture: a Reference Model for Sustainable Consumptiom? In: EnANPAD, 34., 2010 Rio de Janeiro. Anais... Rio de Janeiro: Anpad, 2010.

ABEP - Associação Brasileira de Empresas de Pesquisa. Critério de Classificação Econômica Brasil 2015. Disponível em: < http://www.abep.org/criterio-brasil>. Acesso em: 02 fev. 2016.

AHUVIA, A. If money doesn't make us happy, why do we act as if does? Journal of Economic Psychology, v. 29, n. 4, p. 491-507, 2008.

ALBINSSON, P. A.; PERERA, Y. From trash to treasure and beyond: the meaning of voluntary disposition. Journal of Consumer Behaviour, v. 8, p. 340-353, 2009.

ALEXANDER, S.; USSHER, S. The Voluntary Simplicity Movement: A Multi-National Survey Analysis in Theoretical Context. Simplicity Institute Report, v. 11a, 2011.

ASSADOURIAN, E. Transforming Cultures: From Consumerism to Sustainability. Journal of Macromarketing, v.20, n. 2, p. 186-191, 2010.

BALLANTINE, P. W.; CREERY, S. The consumption and disposition behaviour of voluntary simplifiers. Journal of Consumer Behaviour, v. 9, n. 1, p. 45-56, 2010.

BAUDRILLARD, J. A Sociedade de Consumo. Lisboa: Edições 70, 2008.

BEKIN, C.; CARRIGAN, M.; SZMIGIN, I. Beyond recycling: 'commons-friendly' waste reduction at new consumption communities. Journal of Consumer Behaviour, v. 6, p. 271-286, 2007.

BOURDIEU, P. O Poder Simbólico. Rio de Janeiro: Bertrand Brasil, 2004.

CHAUVEL, M. A.; SUAREZ, M. C. Consumo, Marketing e Sustentabilidade. In: CHAUVEL, M. A.; COHEN, M. (Orgs.). Ética, Sustentabilidade e Sociedade: Desafios da Nossa Era. Rio de Janeiro: Mauad X, 2009.

CLEVELAND, M.; CHANG, W. Migration and materialism: The roles of ethnic identity, religiosity, and generation. Journal of Business Research, v. 62, n. 10, 2009.

CRAIG-LEES, M.; HILL, C. Understanding Voluntary Simplifiers. Psychology \& Marketing, v. 19, n. 2, p. 187-210, 2002.

CSIKSZENTMIHALYI, M. If We Are So Rich, Why Aren't We Happy? American Psychologist, v. 54, n. 10, 1999.

2000.

The Costs and Benefits of Consuming. Journal of Consumer Research, v. 27, p. 267-272,

ELGIN, D. Living More Simply and Civilization Revitalization. In: GOODWIN, N. R.; ACKERMAN, F.; KIRON, D. (Orgs.). The Consumer Society. Washington, D. C., Covelo, California: Island Press, 1997.

Voluntary Simplicity and The New Global Challenge. In: SCHOR, J. B.; HOLT, D. B. (Orgs). The Consumer Society Reader. New York: The New Press, 2000.

Paulo: Cultrix, 2012

ELGIN, D.; MITCHELL, A. Voluntary Simplicity. The CoEvolution Quarterly, n. 14, Summer, $1977 \mathrm{~b}$. Voluntary Simplicity: Life-style of the Future? The Futurist, 1977a.

ETZIONI, A. Voluntary simplicity: Characterization, select psychological implications, and societal consequences. Journal of Economic Psychology, v. 19, p. 619-643, 1998.

GOODWIN, N. R. Scope and Definition: Overview Essay. In: GOODWIN, N. R.; ACKERMAN, F.; KIRON, D. (Orgs.). The Consumer Society. Washington, D. C., Covelo, California: Island Press, 1997.

GREGG, R. Voluntary Simplicity. The CoEvolution Quarterly, n. 14, Summer, 1977.

HOLBROOK, M. B. The Millennial Consumer in the Texts of Our Times: Experience and Entertainment. Journal of Macromarketing, v. 20, p. 178-192, 2000.

HSEE, C. K.; YANG, Y.; LI, N.; SHEN, L. Wealth, Warmth, and Well-Being: Whether Happiness Is Relative or Absolute Depends on Whether It Is About Money, Acquisition, or Consumption. Journal of Marketing Research, v. 46, n. 3, p. 396409, 2009.

HUNEKE, M. E. The Face of the Un-Consumer: An Empirical Examination of the Practice of Voluntary Simplicity in the United States. Psychology \& Marketing, v. 22, n. 7, p. 527-550, 2005.

JOHNSTON, T. C.; BURTON, J. B. Voluntary Simplicity: Definitions and Dimensions. Academy of Marketing Studies Journal, v. 7, n. 1, 2003. 
KARABATI, S.; CEMALCILAR, Z. Values, materialism, and well-being: A study with Turkish university students. Journal of Economic Psychology, v.31, n. 4, p. 624-633, 2010.

KIRON, D. Consumption in the Affluent Society: Overview Essay. In: GOODWIN, N. R.; ACKERMAN, F.; KIRON, D. (Orgs.). The Consumer Society. Washington, D. C., Covelo, California: Island Press, 1997.

KOZINETS, R. V. On Netnography: Initial Reflections on Consumer Research Investigations of Cyberculture. Advances in Consumer Research, v. 25, p. 366-371, 1998.

LEE, D. J.; SIRGY, J.; LARSEN, V.; WRIGHT, N. D. Developing a Subjective Measure of Consumer Well-Being. Journal of Macromarketing, v. 22, n. 2, p. 158-169, 2002.

LEONARD-BARTON, D. Voluntary Simplicity Lifestyles and Energy Conservation. Journal of Consumer Research, v. 8, p. 243-252, 1981.

LEVY, S. J. Symbols For Sale. Harvard Business Review, v. 37, n. 4, p. 117 - 124, 1959.

MCCRACKEN, G. Cultura e Consumo: Novas Abordagens ao Caráter Simbólico dos Bens e das Atividades de Consumo. Rio de Janeiro: Mauad, 2003

MCDONALD, S.; OATES, C. J.; YOUNG, C. W.; HWANG, K. Toward Sustainable Consumption: Researching Voluntary Simplifiers. Psychology \& Marketing, v. 23, n. 6, p. 515-534, 2006.

MURPHY, P. L. The Commodified Self in Consumer Culture: A Cross-Cultural Perspective. Journal of Social Psychology, v.40, p. 636-647, 2000.

OATES, C.; MCDONALD, S.; ALEVIZOU, P.; HWANG, K.; YOUNG, W.; MCMORLAND, L. Marketing sustainability: Use of information sources and degrees of voluntary simplicity. Journal of Marketing Communications, v. 14, n. 5, p. 351-365, 2008.

ROCHA, A.M.C.; SILVA, J.F. Inclusão Social e Marketing na Base da Pirâmide: Uma Agenda de Pesquisa. RAE Eletrônica, v. 7, n. 2, 2008.

RUBIN, H. J.; RUBIN, I. S. Qualitative Research: The Art of Hearing Data. Thousand Oaks: Sage Publication, 2004.

SHAMA, A. Coping with Stagflation: Voluntary Simplicity. Journal of Marketing, v. 45, p. 120-134, 1981.

SHAW, D.; MORAES, C. Voluntary simplicity: an exploration of market interactions. International Journal of Consumer Studies, v. 33, p. 215-223, 2009.

SHAW, D.; NEWHOLM, T. Voluntary Simplicity and the Ethics of Consumption. Psychology \& Marketing, v. 19, n. 2, p. 167-185, 2002.

SHI, D. E. The Quaker Ethic: Plain Living and High Thinking in American Culture. In: GOODWIN, N. R.; ACKERMAN, F.; KIRON, D. (Orgs.). The Consumer Society. Washington, D. C., Covelo, California: Island Press, 1997.

WEISS, R. S. Loneliness: The experience of emotional and social isolation. Cambridge, MA, US: The MIT Press, 1973.

ZAVESTOSKI, S. The social-psychological bases of anti-consumption attitudes. Psychology and Marketing, v. 19, n. 2, p. 149-165, 2002. 